\title{
RANCANG BANGUN SISTEM PENDATAAN NILAI AKADEMIK SISWA BERBASIS WEB MENGGUNAKAN PHP DAN MYSQL DI SMA ISLAM HASANUDDIN KESAMBEN
}

\author{
${ }^{[1]}$ Abdi Pandu Kusuma, ${ }^{[2]}$ Tedhi Widodo \\ ${ }^{[1],[2]}$ Universitas Islam Balitar
}

\begin{abstract}
Abstrak: Seiring dengan teknologi yang berkembang dengan pesat dan semakin canggih, khususnya bidang teknologi informasi sudah banyak hasil yang telah dicapai oleh manusia. Informasi saat ini sudah menjadi bagian yang tidak terpisahkan lagi dari kehidupan manusia. Dalam hal ini mengenai sistem pendataan nilai akademik siswa yang ada di SMA Islam Hasanuddin Kesamben masih menggunakan sistem manual yang belum terintegrasi dengan satu dan lainnya. Penelitian ini membahas tentang pendataan nilai akademik siswa Dengan adanya Sistem Pendataan Nilai Akademik Siswa Berbasis Web Offline yang berfungsi sebagai informasi sekolah, informasi guru dan siswa, informasi jadwal mengajar guru, informasi jadwal pelajaran siswa dan nilai UTS, UAS dan Ulangan Harian diharapkan akan mempermudah dalam pendataan nilai siswa. Software yang digunakan untuk merancang dan mendesain sistem adalah bahasa pemrograman HTML, PHP, PhpMyAdmin sebagai sebuah tools untuk membantu mengelola basis data MySQL, text editor Macromedia Dreamweaver MX 2004, xampp-win32-1.6.8-VC9, dan image editor Adobe Photoshop CS. Sistem pendataan nilai akademik siswa ini diharapkan dapat mempermudah dan membantu sekolah dalam melakukan pengelolaan data nilai akademik siswa sekolah. Karena sistem ini mengintegrasikan beberapa proses yang penting di dalam mengelola data-data yang berhubungan dengan nilai akademik siswa sekolah sehingga kualitas dari informasi yang dihasilkan akan cepat dan akurat lebih baik jika dibandingkan dengan menggunakan sistem yang sebelumnya yaitu secara manual.
\end{abstract}

Kata Kunci : Pendataan Berbasis Web, Pendataan Siswa, Akademik

\section{Pendahuluan}

Lembaga pendidikan saat ini terus mengalami perkembangan pesat seiring dengan laju perkembangan Teknologi Informasi yang sangat beraneka ragam, diperlukan peningkatan kualitas dan mekanisme pelayanan di bidang pendidikan agar lebih berdaya guna dan berhasil guna, sehingga Sumber Daya Manusia (SDM) yang diciptakan dapat berpartisipasi dalam membangun masyarakat sesuai dengan kemampuannya.

Masalah yang dapat diidentifikasikan dari perancangan sistem pendataan akademik siswa berbasis web offline yang berjalan pada SMA Islam Hasanuddin Kesamben diantaranya meliputi sistem yang berjalan selama ini untuk mendapatkan informasi mengenai nilai ujian, kehadiran, dan jadwal pelajaran siswa masih bersifat manual, tidak adanya sistem informasi pendataan akademik siswa yang bisa diakses setiap saat baik oleh pihak SMA Islam Hasanuddin, maupun oleh orang tua siswa, serta pengolahan data akademik siswa masih dilakukan secara manual diantaranya data akademik siswa disimpan dalam modul-modul yang tidak terpisah atau tidak terintegrasi sehingga menyebabkan banyak permasalahan diantaranya redudansi data dan keterlambatan dalam menyajikan informasi akademik siswa.

\section{a. Rancang bangun}

\section{LANDASAN TEORI}

Perancangan/rancang merupakan serangkaian prosedur untuk menerjemahkan hasil analisa dari sebuah sistem ke dalam bahasa pemrograman untuk mendeskripsikan dengan detail bagaimana 
komponen-komponen sistem di implementasikan. sedangkan pengertian pembangunan/bangun sistem adalan kegiatan menciptakan sistem baru naupun mengganti atau memperbaiki sistem yang telah ada baik secara keseluruhan maupun sebagian (Pressman, 2002) ${ }^{[1]}$.

\section{b. Sistem}

Jogiyanto H.M (2000: 683) ${ }^{[2]}$, "Sistem adalah suatu kesatuan yang terdiri dari dua atau lebih komponen atau subsistem yang saling berinteraksi untuk mencapai tujuan." Sedangkan menurut Nugroho (2004:1), bahwa sistem adalah seperangkat komponen yang saling berhubungan yang berfungsi mengumpulkan, memproses, menyimpan dan mendistribusikan informasi untuk mendukung pembuatan keputusan dan pengawasan dalam organisasi.

\section{c. Pendataan}

Data berasal dari DATUM yang berarti materi atau kumpulan fakta yang dipakai untuk keperluan suatu analisa, diskusi, presentasi ilmiah, atau tes statistik. Bila dilihat menurut asal sumbernya, data dibagi menjadi 2 kelompok, yaitu data primer dan data sekunder. Sehingga setiap penelitan pasti memerlukan data sebagai bahan analisa. Sumber : http://carapedia.com/ pengertian_definisi_data _menurut_para_ahli_info505.html di akses tanggal 15 Juli 2014.

\section{d. Web}

Sejarah web dimulai pada bulan maret 1989 ketika Tim Berner-Lee yang bekerja di Laboratorium Fisika Partikel Eropa atau yang dikenal dengan nama CERN (Consei European pour la Recherce Nuclaire) yang berada di Genewa, swiss, mengajukan protokol (suatu tatacara untuk berkomunikasi) sistem distribusi informasi internet yang digunakan untuk berbagai informasi diantara fisikiawan. Protocol inilah yang selanjutnya dikenal sebagai protocol World Wide Web dan dikembangkan oleh World Wide Web Consortium (W3C). sebagaimana diketahui, W3C adalah konsorsium dari sejumlah organisasi yang berkempentingan dalam pengembangan berbagai standar yang berkaitan dengan web.

\section{e. Relasional Database}

1. Basis Data (Database)

Istilah basis data (database) banyak menimbulkan interpretasi yang berbeda. Basis data (database) adalah suatu susunan/kumpulan data operasional lengkap dari suatu organisasi atau perusahaan yang diorganisir atau dikelola dan disimpan secara terintegritasi dengan menggunakan metode tertentu menggunakan komputer sehingga mampu menyediakan informasi yang optimal yang diperlukan pemakainya. Menurut Fathansyah (2001:32), "Basis Data (Database) merupakan Salah satu komponen yang paling penting di dalam sistem informasi karena merupakan dasar dalam menyediakan informasi bagi pemakai."

\section{Relasional (Relationship)}

Janner Simarmata dan Iman Paryudi (2006), struktur yang mendasari suatu basisdata adalah model data yang merupakan kumpulan alat-alat konseptual untuk mendeskripsikan data, relasi data, data semantic dan batasan konsistensi. Untuk mengilustrasikan konsep model data salah satunya menggunakan Entity Relationship Diagram (ERD).

$E R D$ didasarkan pada persepsi terhadap dunia nyata yang tersusun atas kumpulan objek-objek dasar yang disebut entitas dan hubungan antarobjek. Entitas adalah sesuatu atau objek dalam dunia nyata yang dapat dibedakan dari objek lain. Entitas digambarkan dalam basisdata dengan kumpulan atribut. Relasi adalah hubungan antara beberapa entitas.

Beberapa nama-nama simbol yang digunakan dalam pembuatan Entity Relationship Diagram $(E R D)$ ditunjukkan pada Tabel 1 berikut : 
TABEL 1.

NAMA SIMBOL DALAM ERD

\begin{tabular}{ll}
\hline Nama Simbol & Keterangan \\
\hline Entitas & $\begin{array}{l}\text { Entitas dimana menggambarkan suatu objek yang dapat diidentifikasikan } \\
\text { dalam sebuah lingkungan. }\end{array}$ \\
Atribut & Atribut memiliki fungsi mendeskripsikan karakter entitas \\
Relasi & Relasi (relationship) untuk menunjukkan sebuah hubungan atau relasi antar \\
(relationship) & entitas. \\
Garis & Garis penghubung adalah sebagai penghubung antara himpunan relasi dengan \\
Penghubung & himpunan entitas dan himpunan entitas dengan atributnya. \\
\hline
\end{tabular}

Diagram keterhubungan entitas adalah suatu grafik yang menggambarkan hubungan antar entitas dalam suatu database. Entitas merupakan individu yang mewakili sesuatu yang nyata dan dapat dibedakan dari sesuatu yang lain. Entitas adalah suatu objek (event) yang menggambarkan sesuatu hal dalam dunia nyata (real world). Setiap entitas memiliki atribut yang menjelaskan karakteristik dari entitas tersebut. Kardinalitas relasi yang terjadi diantara dua himpunan entitas ada tiga yaitu:

1). Satu ke satu (One to one)

Hubungan relasi satu ke satu yaitu setiap entitas pada himpunan entitas A berhubungan paling banyak dengan satu entitas pada himpunan entitas B.

2). Satu ke banyak (One to many)

Setiap entitas pada himpunan entitas A dapat berhubungan dengan banyak entitas pada himpunan entitas B, tetapi setiap entitas pada entitas B dapat berhubungan dengan satu entitas pada himpunan entitas A.

3). Banyak ke banyak (Many to many)

Setiap entitas pada himpunan entitas A dapat berhubungan dengan banyak entitas pada himpunan entitas B.

\section{f. DFD (Data Flow Dagram)}

Jogiyanto, HM (2005) ${ }^{[2]}$, mengatakan bahwa "Data Flow Diagram (DFD) merupakan alat yang digunakan untuk menggambarkan suatu sistem yang telah ada atau sistem baru yang akan dikembangkan secara logika tanpa mempertimbangkan lingkungan fisik dimana data tersebut mengalir ataupun lingkungan fisik dimana data tersebut akan disimpan Simbol-simbol dalam DFD." Simbolsimbol dalam $D F D$ ditunjukkan pada Tabel berikut :

TABEL 2

NAMA SIMBOL DALAM DFD

\begin{tabular}{|c|c|}
\hline Nama Simbol & Keterangan \\
\hline Entitas & $\begin{array}{l}\text { Merupakan keseluruhan lingkungan diluar sistem yang dapat berupa orang, } \\
\text { organisasi atau sistem lainnya yang berada dilingkungan luarnya yang akan } \\
\text { memberikan input atau menerima output dari sistem.. }\end{array}$ \\
\hline Proses Data & $\begin{array}{l}\text { Kegiatan atau kerja yang dilakukan oleh orang, mesin atau komputer dari } \\
\text { hasil suatu arus data yang masuk ke dalam proses untuk menghasilkan arus } \\
\text { data yang akan keluar dari proses. }\end{array}$ \\
\hline Aliran Data & $\begin{array}{l}\text { Menunjukkan arus dari data yang dapat berupa masukan untuk sistem atau } \\
\text { hasil dari proses sistem. }\end{array}$ \\
\hline Penyimpanan Data & Merupakan simpanan dari data. \\
\hline
\end{tabular}

\section{g. PHP}

Abdul Kadir (2004) $)^{[4]}$, bahwa "PHP (Hypertext Preprocessor) merupakan salah satu dari bahasa pemrograman berbasis website." PHP bersifat server-side programming, artinya kode PHP 
yang ditulis akan dieksekusi di sisi server sehingga pengunjung tidak dapat melihat source code dari skrip PHP yang dibangun.

\section{h. Website}

Abdul Kadir (2004) $)^{[4]}$, "Website adalah suatu media publikasi elektronik yang terdiri dari halaman-halaman web (web page) yang terhubung satu dengan yang lain menggunakan link yang dilekatkan pada suatu teks atau image." Website dibuat pertama kali oleh Tim Barners Lee pada tahun 1990. Website dibangun dengan menggunakan bahasa Hypertext Markup Language (HTML) dan memanfaatkan protocol komunikasi Hypertext Transfer Protocol (HTTP) yang terletak pada application layer pada referensi layer OSI. Halaman website diakses

\section{i. Web Browser dan Web Server}

Onno, W. Purbo Dan Aang Arif Wahyudi., (2001: 18), "Web Browser adalah program perangkat lunak pada sisi client yang bertugas mengambil serta menampilkan informasi dalam web dari server." Sedangkan web server merupakan server yang bertugas mengatur mekanisme layanan web.

\section{j. MySQL}

Butcher (2003: 12), "MySQL adalah perangkat lunak sistem manajemen basis data SQL atau DBMS". MySQL adalah perangkat lunak gratis yang berada dibawah lisensi GNU General Public Lincense (GPL), yang juga menjual dibawah lisensi komersial untuk kasus-kasus dimana penggunaanya tidak cocok dengan GPL.

\section{k. Dreamweaver MX}

Mutmainah (2006:2) ${ }^{[5]}$, "Dreamweaver merupakan program profesional editor HTML visual yang digunakan untuk mengelola situs dan menata layout halaman web." Saat ini versi terbaru dari Dreamweaver yang dikeluarkan oleh Macromedia adalah Dreamweaver MX 2004.

Pada versi ini, tampilannya mengalami perubahan yang kaya akan warna dan area kerjanya menjadi lebih ringkas dan efisien. Hal ini dapat dilihat dengan peletakan tombol-tombol dan panelpanel yang dapat minimize (disembunyikan) untuk menghemat area kerja.

\section{Bahasa Pemograman}

Bahasa yang dipakai dalam pembuatan Program ini adalah menggunakan Xampp. XAMPP merupakan tool yang menyediakan paket perangkat lunak ke dalam satu buah paket. Dengan menginstall XAMPP maka tidak perlu lagi melakukan instalasi dan konfigurasi web server Apache, PHP dan MySQL secara manual. XAMPP akan menginstalasi dan mengkonfigurasikannya secara otomatis untuk anda atau auto konfigurasi.

\section{Metode Penelitian}

Sekolah adalah tempat belajar mengajar bagi siswa, dimana seharusnya pihak sekolah selalu berusaha meningkatkan pelayanannya untuk siswa. Terutama dalam pelayanan yang menyangkut akademik. Sejauh ini jika siswa ingin melakukan kegiatan akademik seperti melihat hasil ujian, memeriksa jadwal dan absensi. Masalah waktu dan jarak juga menjadi kendala, siswa harus datang ke sekolah untuk melakukan kegiatan akademik dan mendapatkan informasi tersebut.

Oleh karena itu, alangkah lebih baiknya diciptakan sebuah sistem yang lebih fleksibel agar siswa dapat melakukan kegiatan akademik siswa seperti diatas tanpa harus bersusah payah datang ke sekolah serta menghemat tenaga dan waktu. 
Berikut proses dari perancangan sistem pendataan nilai akademik siswa berbasis web :

A. Perancangan Proses Menggunakan Diagram Konteks

Adapun DFD tentang sistem pendataan nilai akademik siswa dapat digambarkan sebagai berikut :

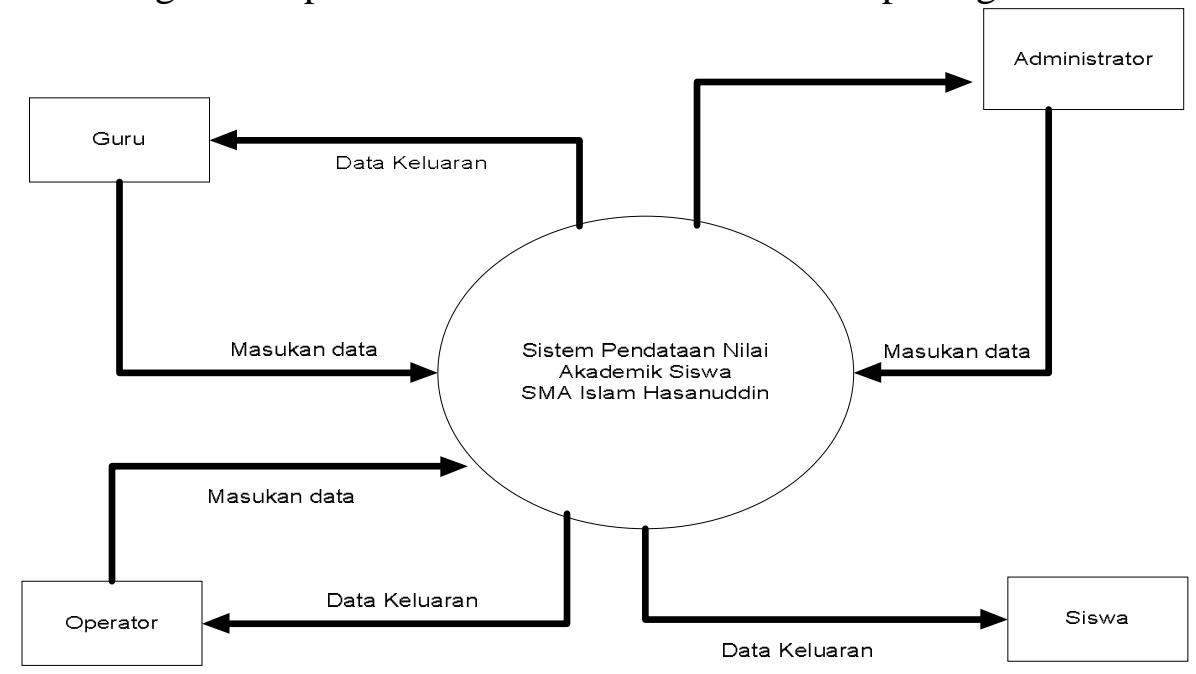

Gambar 1. Diagram Konteks

Pada gambar 1 digambarkan aliran terdiri dari proses yang menggambarkan aliran-aliran data antara sistem dengan bagian-bagian luar sistem yang merupakan sumber arus data. Diagram tersebut memperlihatkan bahwa sistem berinteraksi dengan empat terminal, yaitu administrator, operator, siswa serta guru.

\section{B. Perancangan Proses Menggunakan DFD Level 1}

Adapun DFD Level 1 tentang sistem pendataan nilai akademik siswa dapat digambarkan sebagai berikut

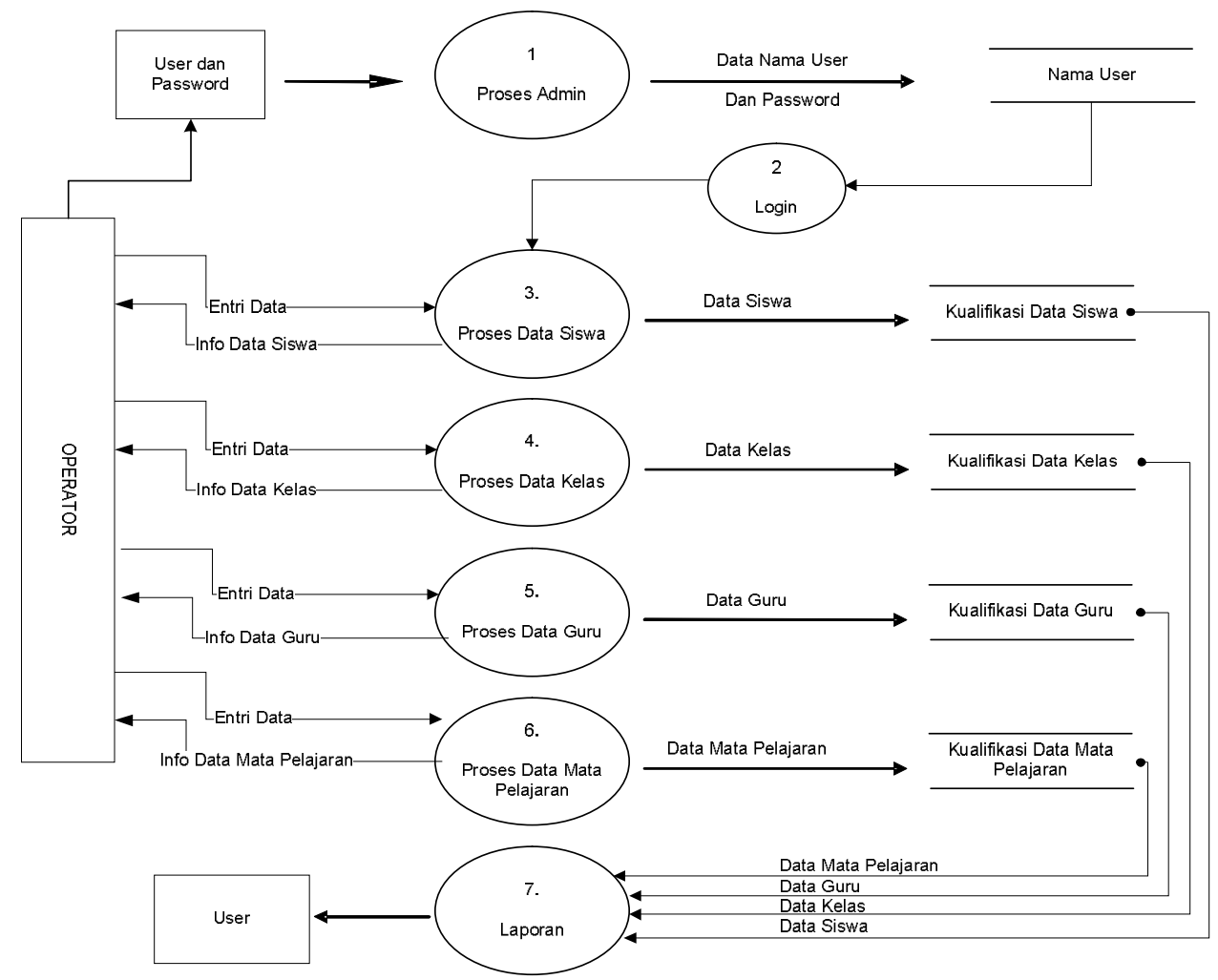

Gambar 2. Data Flow Diagram Level 1 
Pada gambar 2 digambarkan proses pengolahan data-data yang saling berhubungan dalam sebuah sistem mulai dari entry (penginputan), penyimpanan sampai dengan penyajian informasi. Sistem Pendataan Nilai Akademik Siswa Berbasis Web dilakukan proses penginputan data-data siswa, kemudian disimpan dalam sebuah database.

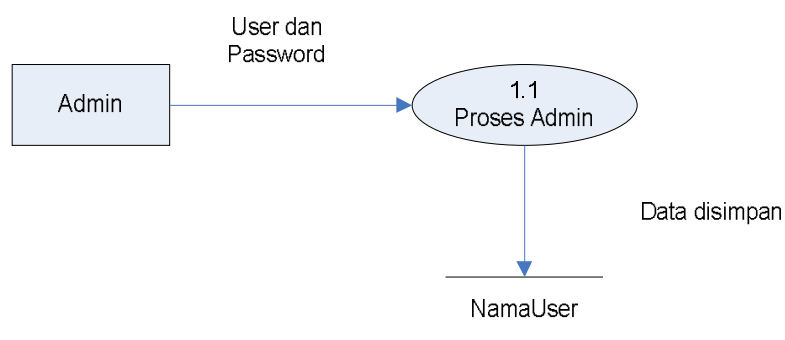

Gambar 3. Data Flow Diagram (DFD) Level 2 Admin

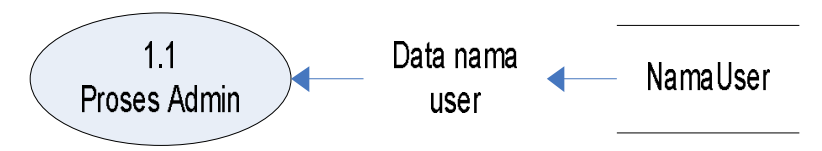

Gambar 4 Data Flow Diagram ( DFD) Level 2 LogIn

Pada gambar 3 dan 4 menjelaskan proses admin yang digunakan untuk menyimpan data namanama user dan password yang berhak mengelola data sistem informasi, selanjutnya data ini disimpan pada tabel password yang akan digunakan oleh administrator untuk entry/ penginputan data tersebut.

\section{Perancangan Proses Menggunakan FlowChart}

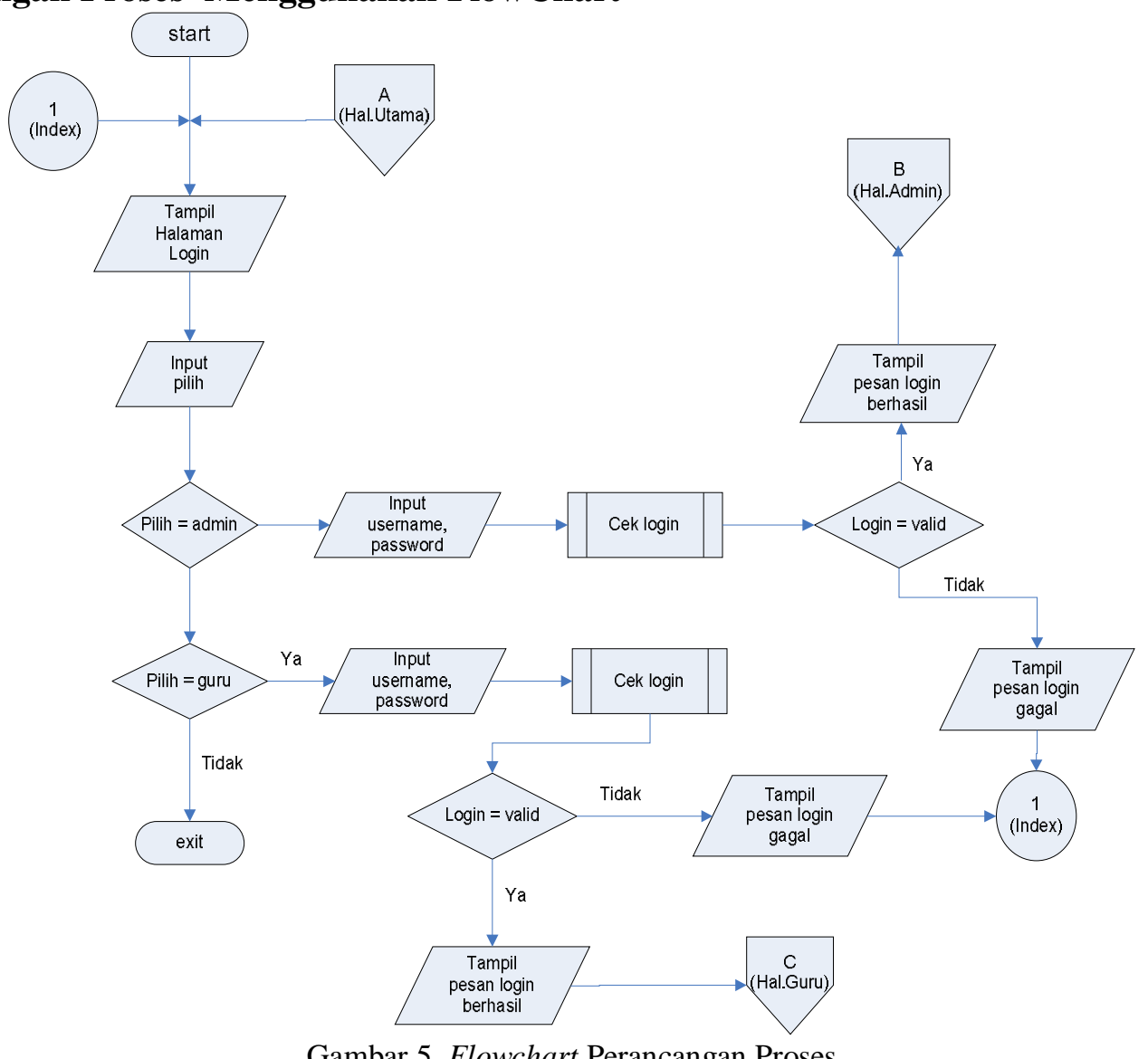

Gambar 5. Flowchart Perancangan Proses 


\section{ERD (Entity Relationship Diagram)}

Berikut Entity Relationship Diagram (ERD) dalam sistem pendataan akademik SMA Islam Hasanuddin Kesamben.

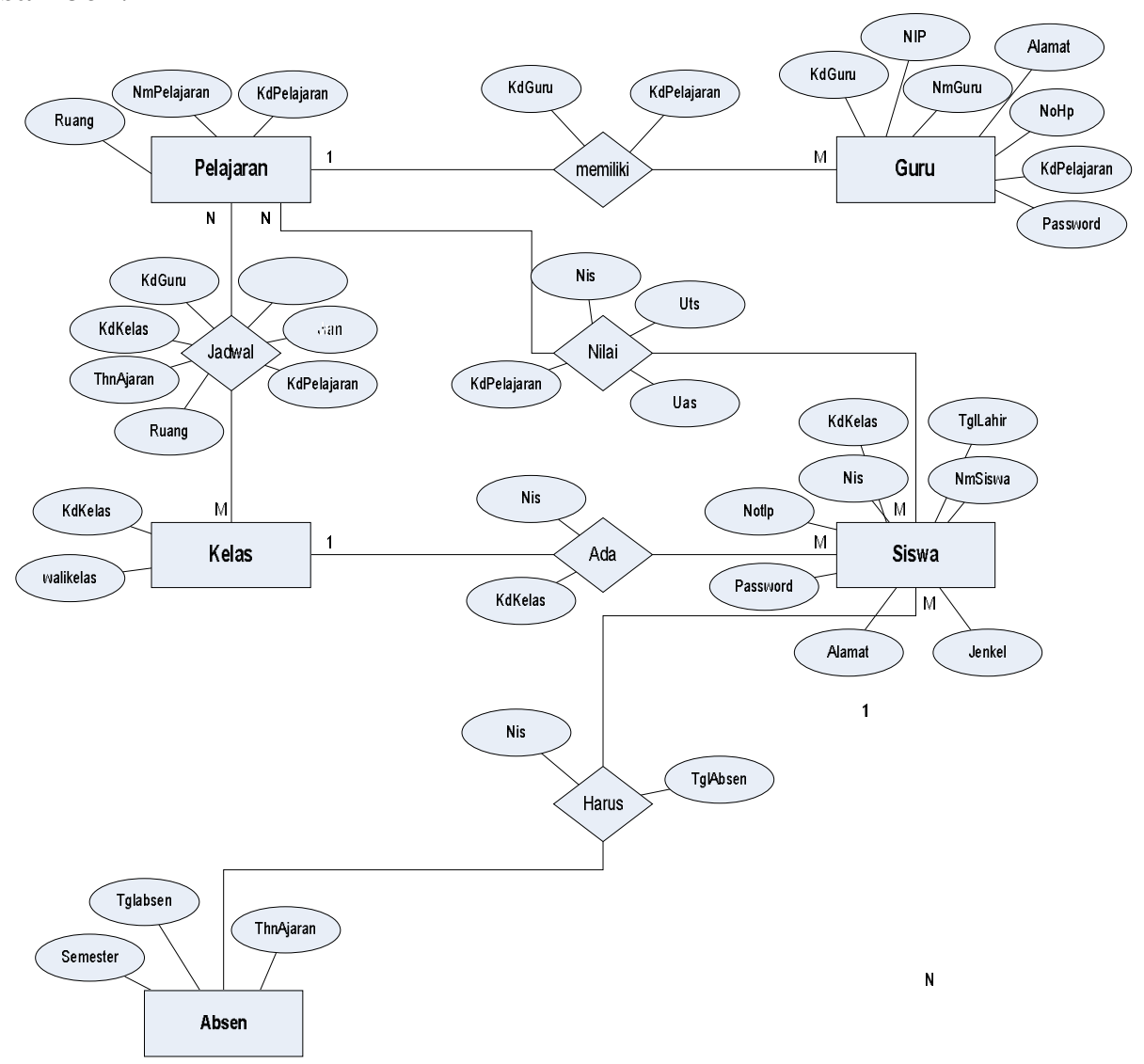

Gambar 6. Entity Relationship Digram

\section{E. Perancangan Basis Data Secara Konseptual}

Perancangan basis data dimulai dengan perancangan secara konseptual (Conceptual Design). Untuk mengelola nilai akademik siswa, hubungan antar entitas ditunjukkan pada Entity Relationship Diagram berikut ini

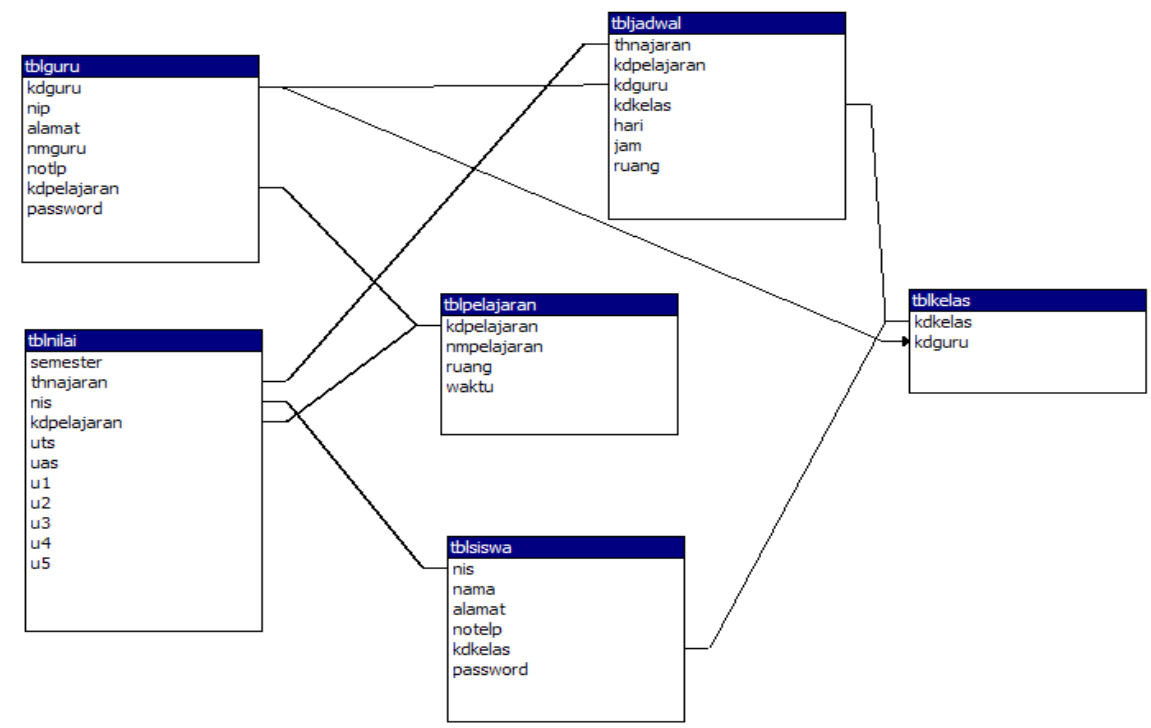

Gambar 7. Desain Konseptual Perancangan Basis Data 


\section{a. Uji Fungsi}

\section{HaSil dan Pembahasan}

Uji fungsionalitas sistem aplikasi dilakukan dengan metode black box testing atau sering disebut behavior testing. Metoda ini dilakukan dengan berfokus pada kebutuhan fungsi dari pada sistem dengan cara mendeteksi adanya error dalam sistem seperti fungsi yang hilang, error dalam antar muka maupun dalam struktur data.

TABEL 3

Pengujian Fungsi

\begin{tabular}{|c|c|c|c|}
\hline No & Kelas Uji & $\begin{array}{l}\text { Teknik } \\
\text { Pengujian }\end{array}$ & Kriteria Evaluasi \\
\hline 1 & $\begin{array}{l}\text { Authentifikasi } \\
\text { Admin }\end{array}$ & Black Box & $\begin{array}{l}\text { Simulasi sistem memeriksa proses LogIn admin berhasil atau tidak } \\
\text { kemudian menyimpan session admin pada saat proses LogIn dan } \\
\text { mematikan session saat admin sudah LogOut sehingga sistem tidak bisa } \\
\text { dibuka lagi kecuali harus LogIn }\end{array}$ \\
\hline 2 & $\begin{array}{l}\text { Authentifikasi } \\
\text { Guru }\end{array}$ & Black Box & $\begin{array}{l}\text { Simulasi sistem memeriksa proses LogIn Guru berhasil atau tidak } \\
\text { kemudian menyimpan session admin pada saat proses LogIn dan } \\
\text { mematikan session saat admin sudah LogOut sehingga sistem tidak bisa } \\
\text { dibuka lagi kecuali harus LogIn }\end{array}$ \\
\hline 3 & $\begin{array}{l}\text { Authentifikasi } \\
\text { Siswa }\end{array}$ & Black Box & $\begin{array}{l}\text { Simulasi sistem memeriksa proses LogIn Siswa berhasil atau tidak } \\
\text { kemudian menyimpan session admin pada saat proses LogIn dan } \\
\text { mematikan session saat admin sudah LogOut sehingga sistem tidak bisa } \\
\text { dibuka lagi kecuali harus LogIn }\end{array}$ \\
\hline 4 & $\begin{array}{l}\text { Authentifikasi } \\
\text { Kepala Sekolah }\end{array}$ & Black Box & $\begin{array}{l}\text { Simulasi sistem memeriksa proses LogIn Kepala Sekolah berhasil atau } \\
\text { tidak kemudian menyimpan session admin pada saat proses LogIn dan } \\
\text { mematikan session saat admin sudah LogOut sehingga sistem tidak bisa } \\
\text { dibuka lagi kecuali harus LogIn }\end{array}$ \\
\hline 5 & $\begin{array}{l}\text { Authentifikasi } \\
\text { Tata Usaha }\end{array}$ & Black Box & $\begin{array}{l}\text { Simulasi sistem memeriksa proses LogIn Tata Usaha berhasil atau tidak } \\
\text { kemudian menyimpan session admin pada saat proses LogIn dan } \\
\text { mematikan session saat admin sudah LogOut sehingga sistem tidak bisa } \\
\text { dibuka lagi kecuali harus LogIn }\end{array}$ \\
\hline 6 & $\begin{array}{l}\text { Pengolahan Data } \\
\text { Master }\end{array}$ & Black Box & $\begin{array}{l}\text { Sistem dapat menampilkan Simulasi pembuatan master data yang terdir } \\
\text { dari tahun pelajaran, pegawai dan menambah, menghapus dan merubah } \\
\text { data }\end{array}$ \\
\hline 7 & $\begin{array}{l}\text { Pengolahan Data } \\
\text { Transaksi }\end{array}$ & Black Box & $\begin{array}{l}\text { Sistem dapat menampilkan Simulasi transaksi data serta menambah, } \\
\text { menghapus dan merubah data }\end{array}$ \\
\hline
\end{tabular}

\section{b. Kerangka Pengujian Data Kuantitatif}

Pengujian perancangan sistem pendataan nilai akademik siswa dimaksudkan untuk mengetahui kesesuaian konsep desain dengan aplikasi yang sudah dibuat. Pengujian dilakukan di Laboratorium komputer SMA Islam Hasanuddin kesamben. Pengguna dihadapkan langsung dengan aplikasi pendataan nilai akademik siswa untuk melakukan serangkaian pengujian terhadap fungsi-fungsi yang ada di dalam sistem.

Pengujian dilakukan dengan memberikan kuesioner kepada masing-masing pemakai, kuesioner ini disebar kepada 10 orang pengguna yang terdiri 9 orang guru sekolah sebagai pengguna, dan 1 orang Tata Usaha sebagai administrator.

Kuesioner ini terdiri dari 2 jenis yaitu untuk guru sekolah yang terdiri dari 10 pertanyaan, dan untuk Tata Usaha yang terdiri dari 6 pertanyaan (contoh kuesioner dapat dilihat pada lampiran). Berikut ini adalah contoh pertanyaan kuesioner untuk diajukan kepada masing- masing level, yaitu guru sekolah dan operator/tata usaha.

TABEL 4

Kuisioner Pengujian Fungsi

\begin{tabular}{lll}
\hline Level & Pertanyaan & Jawaban \\
\hline Guru & 1. Apakah tampilan awal dari aplikasi sistem & 1. Sangat \\
Sekolah & pendataan nilai akademik siswa ini menarik? & Setuju \\
& 2. Apakah Anda setuju dengan adanya sistem & 2. Sangat \\
& pendataan nilai akademik siswa berbasis web? & Setuju \\
& 3. Apakah menurut Anda sistem pendataan nilai & 3. Ragu-ragu \\
\hline
\end{tabular}




\begin{tabular}{|c|c|c|}
\hline \multicolumn{3}{|c|}{$\begin{array}{l}\text { akademik berbasis web ini mudah dipelajari dan } \\
\text { digunakan? }\end{array}$} \\
\hline & $\begin{array}{l}\text { 4. Apakah menurut Anda sistem ini membantu } \\
\text { mengolah data sekolah? }\end{array}$ & 4. Setuju \\
\hline & $\begin{array}{l}\text { 5. Apakah menurut Anda sistem ini membantu } \\
\text { mengolah data tahun ajaran? }\end{array}$ & $\begin{array}{l}\text { 5. Sangat } \\
\text { Setuju }\end{array}$ \\
\hline & $\begin{array}{l}\text { 6. Apakah menurut Anda sistem ini membantu } \\
\text { mengolah data mata pelajaran? }\end{array}$ & $\begin{array}{l}\text { 6. Sangat } \\
\text { Setuju }\end{array}$ \\
\hline & $\begin{array}{l}\text { 7. Apakah menurut Anda sistem ini membantu } \\
\text { mengolah data kelas? }\end{array}$ & 7. Setuju \\
\hline & $\begin{array}{l}\text { 8. Apakah menurut Anda sistem ini mempermudah } \\
\text { mengolah data nilai siswa? }\end{array}$ & 8. Setuju \\
\hline & $\begin{array}{l}\text { 9. Apakah antarmuka sistem pendataan akademik } \\
\text { siswa berbasis web ini terlihat menarik? }\end{array}$ & 9. Setuju \\
\hline & $\begin{array}{l}\text { 10. Apakah sistem pendataan nilai akademik siswa } \\
\text { berbasis web ini dapat menampilkan informasi nilai } \\
\text { siswa yang dibutuhkan? }\end{array}$ & $\begin{array}{l}\text { 10. Sangat } \\
\text { Setuju }\end{array}$ \\
\hline \multirow[t]{6}{*}{$\begin{array}{l}\text { Operator/Tata } \\
\text { Usaha }\end{array}$} & $\begin{array}{l}\text { 1. Apakah tampilan awal dari aplikasi sistem } \\
\text { pendataan nilai akademik siswa ini menarik? }\end{array}$ & $\begin{array}{l}\text { 1. Sangat } \\
\text { Setuju }\end{array}$ \\
\hline & $\begin{array}{l}\text { 2. Apakah Anda setuju dengan adanya sistem } \\
\text { pendataan nilai akademik siswa berbasis web? }\end{array}$ & $\begin{array}{l}\text { 2. Sangat } \\
\text { Setuju }\end{array}$ \\
\hline & $\begin{array}{l}\text { 3. Apakah menurut Anda sistem pendataan nilai } \\
\text { akademik berbasis web ini mudah dipelajari dan } \\
\text { digunakan? }\end{array}$ & 3. Ragu-ragu \\
\hline & $\begin{array}{l}\text { 4. Apakah antarmuka sistem pendataan akademik } \\
\text { siswa berbasis web ini terlihat menarik? }\end{array}$ & 4. Setuju \\
\hline & $\begin{array}{l}\text { 5. Apakah sistem pendataan nilai akademik siswa ini } \\
\text { dapat menampilkan informasi yang dibutuhkan? }\end{array}$ & $\begin{array}{l}\text { 5. Sangat } \\
\text { Setuju }\end{array}$ \\
\hline & $\begin{array}{l}\text { 6. Apakah menurut anda sistem pendataan nilai } \\
\text { berbasis web ini dapat membantu pekerjaan anda } \\
\text { dalam mendata nilai siswa? }\end{array}$ & $\begin{array}{l}\text { 6. Sangat } \\
\text { Setuju }\end{array}$ \\
\hline
\end{tabular}

TABEL 5

Teknik Penilaian

\begin{tabular}{lll}
\hline No & Kriteria & Bobot \\
\hline 1 & Sangat Tidak Setuju & 10 \\
2 & Tidak Setuju & 10 \\
3 & Ragu-ragu & 10 \\
4 & Setuju & 10 \\
5 & Sangat Setuju & 10 \\
\hline
\end{tabular}

\section{c. Teknik Analisis Data}

Angket dalam penelitian ini disusun menurut skala likert. Untuk keperluan pengolahan data statistik, tiap pilihan jawaban diberi bobot dengan ketentuan sebagai berikut :

a. Sangat tidak setuju $(1 \times 10=10)$

b. Tidak setuju $(2 \times 10=20)$

c. Ragu-ragu $(3 \times 10=30)$

d. Setuju $(4 \times 10=40)$

e. Sangat setuju $(5 \times 10=50)$

Jumlah pertanyaan yang harus ditanggapi guru dan operator/tata usaha dalam angket penelitian ini sebanyak 16 pertanyaan. Rumus yang digunakan untuk menentukan kriteria respon guru dan tata usaha adalah :

$$
\text { skor }=\frac{\text { skortotal }}{\text { skormaksimum }} \times 100 \%
$$


Setelah dilakukan penyebaran angket, maka hasil penyebaran angket tersebut di analisis dengan penyajian data dalam bentuk table data ordinal. Pada table berikut akan disajikan kolerasi skor yang diperoleh dari penyebaran angket dengan table kriteria respon para guru dan tata usaha.

TABEL 5

\begin{tabular}{cllll}
\multicolumn{5}{c}{ HASIL PENGOLAHAN DATA KUISIONER } \\
\hline No & Aspek Pengujian & Skor & Prosentase & Keterangan \\
\hline 1. & Ketertarikan Pengguna & 44 & $8.8 \%$ & Sangat setuju \\
2. & $\begin{array}{l}\text { Pengujian Prosedur pengoperasian Sistem } \\
\text { 3. Pendataan Nilai Akademik Berbasis Web }\end{array}$ & 45 & $9 \%$ & Sangat Setuju \\
3. & $\begin{array}{l}\text { Pengujian navigasi Aplikasi Sistem pendataan Nilai } \\
\text { Siswa berbasis web }\end{array}$ & 36 & $7.2 \%$ & Setuju \\
4. & Learnability & 46 & $9.2 \%$ & Sangat setuju \\
5. & $\begin{array}{l}\text { Pengujian user interaction Sistem Pendataan Nilai } \\
\text { Akademik Siswa }\end{array}$ & 34 & $6.8 \%$ & Setuju \\
6. & $\begin{array}{l}\text { Antar muka } \\
\text { 7. Pengujian terhadap performance atau performa }\end{array}$ & 35 & $7 \%$ & Setuju \\
8. $\begin{array}{l}\text { aplikasi pendataan nilai akademik siswa } \\
\text { Pengujian terhadap compatibility sistem pendataan }\end{array}$ & 43 & $7 \%$ & Setuju \\
nilai akademik siswa & $\begin{array}{l}\text { Pengujian Usability dari sistem pendataan nilai } \\
\text { akademik siswa }\end{array}$ & 36 & $7.2 \%$ & Sangat setuju \\
$\quad$ Total rata-rata & 39 & $7.87 \%$ & Setuju \\
\hline
\end{tabular}

Dari pengolahan data di atas skor rata-rata aspek pengujian 39 dan prosentasi $7.87 \%$ responden menyatakan sangat setuju bahwa perancangan dan implementasi sistem pendataan nilai akademik siswa berbasis web yang di rancang sesuai dengan fungsinya dan sesuai dengan apa yang di rancang, sehingga dapat membantu guru maupun tata usaha sekolah dalam layanan maupun pengolahan dalam pendataan nilai akademik siswa.

\section{KeSIMPULAN}

Berdasarkan hasil pengujian dan pembahasan yang telah dilakukan pada bab-bab sebelumnya. Maka dalam mengakhiri pembahasan "Rancang Bangun Sistem Pendataan Nilai Akademik di SMA Islam Hasanuddin Kesamben dapat ditarik kesimpulan, diantaranya :

a. Dengan memakai konsep sistem pendataan nilai akademik siswa berbasis web offline diharapkan bisa menciptakan suatu sistem yang bisa menangani pendataan akademik siswa dengan sistim terpusat agar lebih efisien dalam pengolahan data

b. Hasil uji dan pengolahan data didapat rata-rata skor 39 dari aspek pengujian. Prosentase aspek pengujian dan rancangan 10 responden menyatakan $78.7 \%$ bahwa sistem pendataan nilai akademik siswa di SMA Islam Hasanuddin yang dirancang sesuai dengan fungsinya dan sesuai dengan apa yang dirancang sehingga dapat digunakan untuk mengelola sistem pendataan sekolah.

\section{DAFTAR PUSTAKA}

Abdul Kadir (2004). Panduan Praktis Membuat Web dengan PHP untuk Pemula, Jakarta, Gramedia Ansari, Saleh (2012). Sistem Informasi Manajemen Sekolah Berbasis Web, Yogyakarta, Lokomedia Bunafit Nugroho, (2012). Panduan Membuat Program Toko dengan PHP, MySQL dan Dream Weaver - Pont of Sale (POS).,Bandung, Alif Media

Jogiyanto H.M (2000:683). Sistem Informasi Akademik Sekolah, Yogyakarta, Lokomedia Mutmainah (2006:2). Belajar Macromedia Dreamweaver MX dengan PHP, Yogyakarta, Andi Nugroho (2004:1). Sistem Informasi Manajemen Sekolah, Jakarta, Salemba

Pressman (2002). Rancang Bangun Sistem, indahpermata.blogspot.com (diakses tanggal 15 Agustus 2014) 